\title{
LA VERGINE MARIA E LA PIENEZZA DEI TEMPI NEL MISTERO DELL'INCARNAZIONE SECONDO SAN PIETRO CRISOLOGO
}

Il mistero dell'Incarnazione, occupa nella teologia di san Pietro Crisologo, vescovo di Ravenna, un posto importante. Se teniamo conto che il suo episcopato si situa nel tempo fra i due Concili di Efeso e di Calcedonia - periodo delle polemiche cristologiche - tale impostazione circa l'insegnamento sulla persona di Cristo risulta pienamente giustificato. Tutto il discorso cristologico viene presentato dal vescovo Pietro, in una prospettiva storico-salvifica, in cui spicca l'evento dell'Incarnazione come momento centrale. La venuta di Cristo nel mondo, apre la nuova epoca dell'economia salvifica: la pienezza del tempo. L'intenzione di questo scritto è quella di delineare quanto l'autore dei 183 sermoni ha detto sul mistero dell'Incarnazione come pienezza del tempo, mettendo in rilievo la figura della Vergine Maria.

\section{LA NASCITA DI CRISTO COME CATEGORIA ERMENEUTICA DELLA STORIA}

Nella teologia di Pier Crisologo, la nascita di Cristo viene presentata come il culmine della storia del mondo: evento, che oltre a dividere il tempo in due parti, prima e dopo Cristo, conferisce ad esso il suo vero e pieno significato. L'Incarnazione pertanto diventa la categoria ermeneutica alla luce della quale il vescovo di Ravenna rilegge ed interpreta la storia. In tale prospettiva, gli avvenimenti storici diventano il luogo privilegiato della manifestazione del disegno salvifico di Dio, il quale gradualmente guida l'umanità attraverso i secoli verso il compimento dei tempi. ${ }^{1}$ Così, la storia dell'umanità fino all'Incarnazione viene considerata tempo di attesa e di maturazione e il senso e lo

${ }^{1}$ Cf. B. Kochaniewicz, La Vergine Maria nei sermoni di san Pietro Crisologo, Roma 1998, 66; F. Sottocornola, Il contenuto mariano dei sermoni di Pietro Crisologo, „Ravennatensia” 8(1971) 13-42; R.Mc Glynn, The Incarnation in the Sermons of Saint Peter Chrysologus, Diss., Chicago 1956; R. Benericetti, Il Cristo nei sermoni di S. Pier Crisologo, Cesena 1995. 
scopo dell'agire di Dio nel corso dei secoli è la preparazione degli uomini ad accogliere il Salvatore. Nella venuta del Ristauratore si compie il senso della storia; è Dio, il Signore dei secoli, che porta la storia al suo compimento.
„A buon diritto, dunque, il Creatore dei tempi attende il tempo del mondo e permette che il secolo sia istruito col lungo trascorrere delle età, perché il mon- do, fatto, più maturo, ricevesse, sia pure in ritardo, il suo ristauratore, poiché prima per ignoranza non era riuscito ad accogliere il suo creatore" ${ }^{2}$.

La preparazione consiste da una parte nella continua e graduale rivelazione della carità di Dio verso l'uomo e dall'altra nella liberazione della creatura dalla paura e dal timore servile. ${ }^{3}$ Iddio interviene nel corso della storia affinché l'uomo impari ad amarlo e a rendergli culto con amore, e non con timore. Per illustrare la sua tesi il Crisologo richiama la figura di Abramo:

„Ecco, perché chiama Abramo dai pagani, gli dà un nome più grande, lo fa padre della fede, lo accompagna per via, lo protegge tra gli stranieri, lo arricchisce di beni, l'onora di successi, lo lega a sé con le promesse, lo sottrae alle offese, lo lusinga con l'ospitalità, lo glorifica con un germoglio non sperato, affinché, riempito di beni così numerosi, attirato da così grande dolcezza dell'amore divino, imparasse ad amare Dio, non a temerlo; a rendergli culto con l'amore, non col timore." ${ }^{4}$

In una prospettiva simile viene interpretata tutta la vita di Mosè. La guida divina della sua storia, l'abbondanza dei doni celesti che gli sono stati concessi, il sostegno durante il cammino verso la terra promessa, sono, per il nostro vescovo, forme della rivelazione dell'amore divino il cui scopo è quello di suscitare nel cuore del servo di Dio una risposta d'amore:

„Per questo chiama Mosé con voce di padre, lo interpella con amore paterno, lo invita ad essere liberatore della sua eredità. Che dire di più? Lo fa Dio [...] lo fornisce di segni miracolosi, lo arma di poteri, comandando vince le guerre con la collaborazione della stessa natura. Lo fa vincere, con i suoi precetti gli concede di trionfare e porta alla sua amicizia tutte le corone di virtù, gli accorda di essere partecipe del regno celeste e gli permette di essere promulgatore della Legge. Tuttavia Mosé ricevette tutte queste cose per essere indotto all'amore; e, quindi, perché fosse così infiammato dall'amore di Dio da amare ardentemente egli steso e da ammonire gli altri affinché amassero".

2 Sermo 140 bis, 4, CCL 24B, 852, SPC 3, 96-97 (SPC = Opere di san Pietro Crisologo. Scrittori dell'Area Santambrosiana, voll. 1-3, Biblioteca Ambrosiana-Città Nuova Editrice, Milano-Roma 1996-1997); altre edizioni: PL 52, 183-666; CCL 24, 24A, 24B.

${ }^{3}$ Cf. Sermo 147, 4, CCL 24B, 910, SPC 3, 146-147; B. Kochaniewicz, La Vergine Maria nei sermoni di san Pietro Crisologo, 66.

4 Sermo 147, 4, CCL 24B, 911, SPC 3, 148-149.

5 Sermo 147, 5, CCL 24B, 911, SPC 3, 148-149. 
La pienezza dei tempi contiene in se stessa una dimensione universale per cui la salvezza non si limita al solo popolo eletto, ma si estende anche ai pagani. Nel periodo di preparazione infatti, non solo gli Ebrei vengono educati ad accogliere il Messia, ma anche i pagani sono oggetto dell'azione di Dio, suscitando in essi il desiderio di vederlo, così che proprio il culto degli idoli sarebbe, secondo Pietro Crisologo, paradossalmente l'espressione di questo desiderio. ${ }^{6}$ Questa bell' intuizione viene espressa nel sermone 147 con le parole seguenti:

,....quando la fiamma della carità divina infiammò i cuori umani e nei sentimenti degli uomini si trasfuse tutta l'ebbrezza dell'amore di Dio, con mente così vulnerata cominciarono a voler vedere Dio con gli occhi della carne.," [...] „Ecco perché l'amore che brama vedere Dio, anche se non ha discernimento, ha tuttavia impegno di devozione. [...] Perciò anche gli stessi pagani fabbricarono simulacri per vedere, nel loro stesso errore, con gli occhi ciò che onoravano."

Nell'epoca nella quale l'umanità veniva preparata all'evento della nascita del Salvatore, Dio, nella sua economia, tracciava alcune tappe da percorrere. Il Crisologo ne distingue tre: tempo prima della Legge, tempo della Legge e tempo della grazia?. Quest'ultimo periodo corisponderebbe alla venuta del Salvatore, che dà inizio alla pienezza dei tempi, l'epoca della restituzione della salute e della vita. ${ }^{10}$ La differenza tra le due epoche è stata delineata per mezzo dell'esempio del Tempio di Gerusalemme: come la Legge permetteva al popolo di avvicinarsi alla porta del Tempio, così la grazia permette loro di entrare dentro. $^{11}$

${ }^{6}$ Cf. Sermo 147, 6, CCL 24B, 912, SPC 3, 148-149: „Sed per haec, quae memorauimus, ubi humana corda flamma diuinae caritatis accendit, et humanis sensibus amoris dei tota se fudit ebrietas, saucia mente coeperunt deum carnalibus uelle oculis intueri"; Sermo 147, 7, CCL 24B, 912, SPC 3, 150-151: „Hinc est quod amor, qui cupit uidere deum, et si non habet iudicium, habet tamen studium pietatis. [...] Denique et ipsi gentiles ob hoc simulacra finxerunt, ut in ipsis erroribus oculis cernerent quod colebant."

7 Sermo 147, 6, CCL 24B, 912, SPC 3, 148-149.

${ }^{8}$ Sermo 147, 7, CCL 24B, 912, SPC 3, 150-151.

${ }^{9}$ Cf. Sermo 59, 9, CCL 24, 333, SPC 1, 398-399: , Ut tribus in diebus trinitatis beneficium panderetur; ut per triduanum tempus humana trium temporum generatio salueretur, id est ante legem, in lege, in gratia."

${ }^{10}$ Cf. Sermo 36, 4, CCL 24, 210, SPC 1, 264-265; B. Kochaniewicz, La Vergine Maria nei sermoni di san Pietro Crisologo, 66: ,... cum utrisque nouissimo et expleto tempore salus redderetur et uita. [...] Unde et propheta annum domini acceptum Christum indicat aduenisse, et apostolus temporis plenitudine Christum uenisse adprobat."

${ }^{11}$ Cf. Sermo 86, 5, CCL 24A, 534, SPC 2, 180-181: „Ut ergo populus, qui stabat foris, intromitteretur, exorat, quia quos lex adducit ad ianuam, gratia intromittit in templum". 


\section{LA NASCITA DEL SALVATORE E LA PIENEZZA DEI TEMPI}

1. Il Natale - storia profana o storia sacra? Il Predicatore, commentando i testi dei Vangeli dell'Infanzia, riconosce la storicità dei fatti raccontati. ${ }^{12}$ Quei dati però, racchiudono un significato più profondo, in modo simile alla natura umana di Cristo che vela quella divina. ${ }^{13}$ Conoscere il senso vero, significa scoprire il senso del disegno divino fin'allora nascosto, la logica dell'agire di Dio, che si manifesta per mezzo dei dati storici ${ }^{14}$. Percui il nostro vescovo di fronte ai fatti storici spesso pone la domanda „perché?” cercando di dare una risposta soddisfacente.

Occorre aggiungere che l'evento della nascita di Cristo illumina gli altri eventi, i quali attingono in esso la pienezza di senso. Nel sermone 140 bis, per esempio, il vescovo Pietro cita il passo del vangelo di Luca: „In quei giorni uscì un editto di Cesare Augusto, perché si facesse il censimento di tutta la terra" (Lc 2,1-2). La spiegazione delle circostanze storiche della nascita di Cristo il vescovo ravennate la trova nel Vangelo di Matteo (Mt 22,21) e la spiega nel modo seguente:

„Alla nascita di Cristo viene censita tutta la terra, poiché il tributo si deve a Cesare, il censimento al Creatore. Sulla moneta c'è il ritratto di Cesare, nell'uomo c'è l'immagine di Dio. Viene censita, dunque, la terra affinché l'immagine del re sia impressa sulla moneta e l'immagine di Dio sia nuovamente riprodotta nell'uomo"15.

2. Eternità di Dio e temporaneità del mondo. Il vescovo di Ravenna molto spesso sottolinea nei suoi sermoni la dimensione trascendente del Figlio di Dio. Egli è coeterno al Padre, trascende il tempo, è al di là della dimensione

12 Cf. Sermo 140, 2, CCL 24B, SPC 3, 90-91: „«In sexto autem mense missus est, inquit, angelus Gabriel in ciuitatem Galilaeae, cui nomen Nazareth, ad uirginem desponsatam uiro, cui nomen erat Ioseph». Locum, tempus, personam sanctus euangelista designat, ut relationis ueritas manifestis ipsarum rerum comprobetur indiciis."

${ }^{13}$ Cf. Sermo 143, 1, CCL 24B, 870, SPC 3, 116-117: „Denique euangelista conceptum uirginis, uirginis partum, sicut humano sermone pandit, ita diuino claudit archano, et hoc facit, ut homo quod credere iussus est, discutere non praesumat."

${ }^{14}$ Cf. Sermo 64, 1, CCL 24A, 379, SPC 2, 18-19: „Orate ergo, ut quia in saeculi obscuritate uersamur, et in carne positi noctis tempus agimus, non diei, lucernam nobis uerbi sui Christus accendat, qua praeuia mysterii caelestis ingrediamur obscura, et gradu lento perueniamus ad scientiae diuinae quantum possumus claritatem, sicut illi magi, qui mentis suae oculos metientes non audent splendori solis aut diurnae se committere claritati, sed nocte tenerum stellae lumen tenerioribus oculis adsumentes ad cubile Christi tenerrimum peruenerunt."

${ }^{15}$ Cf. Sermo 140bis, 1, CCL 24, 851, SPC 3, 94-95: „ «Factum est, inquit, in diebus illis, exiit edictum a Caesare Augusto, ut profiteretur uniuersus orbis terrae. Haec professio prima facta est». Christo nascente uniuersus profitetur orbis, quia census Caesari, professio debetur auctori. In nummo est imago Caesaris, in homine est imago Dei. Profitetur itaque orbis, ut similitudo regis formetur in nummo." 
temporale. Dio Padre genera il suo Figlio nell'eternità, perché non conosce il tempo, non dà inizio, perché non conosce inizio ${ }^{16}$. E come il tempo implica l'atemporalità, così l'eternità esclude il tempo ${ }^{17}$. Per poter sottolineare ancora di più atemporalità del Verbo, il Crisologo lo chiama „Auctor temporum” e „Conditor dierum" ${ }^{18}$. Per mezzo di tali titoli, l'Oratore vuole accennare che il Figlio creando il mondo non solo ha dato inizio alla storia, ma come Signore, la trascende e la guida al suo compimento.

3. Il tempo, nuova dimensione di Dio. Il momento in cui il Verbo si è fatto carne viene interpretato come una umiliazione, sottomissione del Signore dei tempi, alle regole del tempo. In un sermone afferma: „Nell'uomo agiva come Dio, nel servo come Signore, per essere schiavo del tempo, mentre era il Creatore e il giudice dei secoli" "9 . Grazie all'Incarnazione, l'eterno e immutabile Figlio di Dio assumendo la dimensione spazio-temporale diventa mutabile, sottomesso alle regole di crescita. L'unica ragione dell'assunzione di tale condizione è la salvezza dell'uomo. In una delle sue omelie il Predicatore afferma: „Christus propter hominem homo natus est et diem suscepit et tempus" ${ }^{20}$. E con la nascita di Cristo inizia, la pienezza dei tempi ${ }^{21}$. Grazie all'Incarnazione, nella persona di Cristo si trovano unite realtà opposte: la divinità e l'umanità, il cielo e la terra, l'eternità e il tempo; la temporalità diventa una dimensione di Dio e Dio accoglie la dimensione del divenire.

Ma nello stesso tempo, Dio concede al tempo e alla storia il vero valore salvifico perché venuta del Figlio di Dio nel mondo ha significato per il tempo e la storia pienezza e compimento di senso. Il tempo diventa condizione e possibilità di salvezza per l'uomo.

\section{Pienezza del tempo e compimento delle promesse vetero-testamentarie.} La pienezza del tempo ha significato anche compimento delle profezie e delle

${ }^{16}$ Cf. Sermo 60, 4, CCL 24, 337, SPC 1, 404-405: „Deus uero pater non genuit in tempore, quia tempus ignorat; non dedit initium, qui initium nescit; non transfudit finem, qui non habet finem, sed sic genuit ex se filium, ut totum quod in se erat, esset et maneret in filio."

17 Sermo 34, 5, CCL 24, 199, SPC 1, 254-255: „Sicut temporalitatem tempus attulit, sic exclusit aeternitas tempus."

18 Sermo 131, 11, CCL 24B, 808, SPC 3, 50-51: „Dierum conditor non tenetur die, temporis auctor tempora nescit.”; Sermo 16, 11, CCL 24, , SPC 1, 144-145: „Auctori temporum tempus opponunt." Sermo XVI, 6. SPC 1, 144.145.

${ }^{19}$ Sermo 162, 6, CCL 24B, 1002, SPC 3, 236-237; Cf. Sermo 140bis, 5, 852, SPC 3, 96-97: „Qui claudit orbem, utero clauditur; naturae auctor nascitur; fit hominum primogenitus hominum creator et temporum."

${ }^{20}$ Sermo 131, 11, CCL 24B, 809, SPC 3, 50-51.

${ }^{21}$ Cf. Sermo 36, 4, CCL 24, 210, SPC 1, 264-265: „Unde et propheta annum domini acceptum Christum indicat aduenisse, et apostolus temporis plenitudine Christum uenisse adprobat dicens: "Post quam uenit temporis plenitudo, misit Deus filium suum»." 
promesse vetero testamentarie. Di fronte all'Incarnazione esse perdono il loro valore, perché ciò che preannunciavano si è già realizzato. Nel sermone 130, per esempio, Pietro di Ravenna esprime tale pensiero in modo seguente:

„Se Mosé ed Elia accorsero sul monte per vedere il Cristo promesso, come mai Abramo non accorse al parto della Vergine, per ottenere, lui che aveva aspettato con tanta pazienza, la benedizione promessa alle genti, cioè alla sua discendenza?"22

La nascita di Cristo viene interpretata come teofania, come manifestazione dell'Invisibile. Il tempo dell'attesa viene compiuto, il desiderio di vedere Dio viene saziato: Dio invisibile si rende visibile. La venuta del Signore viene considerata come il momento di tale manifestazione. La pienezza dei tempi è unita con l'epifania del Dio Incarnato. Nel sermone 147 egli afferma:

„Nessuno dunque, creda un'offesa a Dio, se Dio è venuto agli uomini per mezzo di un uomo e ha preso da noi il mezzo per essere da noi visto." ${ }^{23}$

5. Pienezza del tempo considerata nelle sue conseguenze. Il tempo dell'Incarnazione viene presentato anche come una nuova creazione. Dio assumendo la natura umana, la purifica, la libera dalla corruzione ${ }^{24}$ e la divinizza, concedendo la pienezza della sua vita. ${ }^{25}$ L'esistenza dell'uomo viene transformata: da creatura terrestre, diventa un essere celeste. ${ }^{26}$ Il Verbo si fece uomo per riparare ciò che nella natura umana aveva distrutto a causa del peccato. ${ }^{27}$ In tale luce il mistero dell'Incarnazione è considerato come ricreazione dell'uomo. Il Verbo, che all'inizio ha creato dal fango il primo uomo, assumendo la carne nel seno della Vergine plasma un uomo nuovo:

„Colui che col suo tocco creò l'uomo dal fango intatto, con la sua nascita da un corpo intatto creò un uomo. La mano che si degnò di prendere il fango per plasmarci, si compiacque di prendere anche la carne per la nostra redenzione" ${ }^{28}$.

22 Sermo 131, 11, CCL 24B, 809, SPC 3, 50-51.

23 Sermo 147, 8, CCL 24B, 913, SPC 3, 150-151.

${ }^{24}$ Cf. Sermo 148, 5, CCL 24B, 922, SPC 3, 156-157: „Quem terrenum fecerat, fecit esse caelestem. Animatum humano spiritu, spiritum uiuificat in diuinum, et sic eum totum tollit in deum, ut in eo quod peccati, quod mortis, quod laboris, quod doloris, quod terrae est, nil relinquat".

25 Cf. Sermo 144, 7, CCL 24B, 883, SPC 3, 126-127: „Audi apostolum dicentem: «Deus erat in Christo mundum reconcilians sibi», sibi utique, non alii. Hic ergo deus, qui in Christo erat, regnum sibi dabat in Christo, et conferebat suscepto corpori, quod semper diuinitate possederat."

26 Cf. Sermo 148, 5, CCL 24B, 921, SPC 3, 156-157.

27 Cf. Sermo 156, 3, CCL 24B, 970, SPC 3, 196-197: „Oritur origo rerum, generatur largitor generis, nascitur auctor naturae, ut repararet naturam, genus redderet, originem recrearet."

${ }^{28}$ Sermo 148, 1, CCL 24B, 917, SPC 3, 152-153. 
Pietro Crisologo, nella sua interpretazione non si limita alla sola dimensione antropologica. Afferma che Cristo, nuovo Adamo, con la sua nascita, inizia il processo della reintegrazione della natura umana corrotta dal peccato, anzi, la restaurazione di tutto il creato.

La pienezza dei tempi significa anche la sconfitta della morte e l'effusione della vita. L'effusione della grazia sull'umanità, frutto del mistero pasquale, ha inizio, proprio nel momento in cui il Verbo assume la natura umana. L'Incarnazione annunzia e mette in rilievo la realtà che otterrà la sua pienezza dopo la Pasqua. Il tempo è il mezzo del quale Dio si serve per donare la sua grazia:

„Dunque, la pioggia celeste si riversò con tranquilla caduta sul vello verginale e tutta l'onda della divinità si nascose nel vello assorbente della nostra carne, in attesa di spargersi, spremuto, dal patibolo della croce, in pioggia di salvezza su tutte le terre...". ${ }^{29}$

Come nota il vescovo di Ravenna, è proprio la grazia che dà la vita, rinnova l'uomo, lo divinizza e lo trasforma in un essere celeste.

Un'altra conseguenza salvifica della pienezza dei tempi è la partecipazione della natura umana alla gloria divina. Il Crisologo per poter più facilmente esprimere il mistero di Dio fatto uomo utilizza l'espressione commercium. Questo termine sottolinea le conseguenze dell'Incarnazione: l'intima unione tra la divinità e l'umanità in Cristo e lo scambio. Il luogo di questo scambio è il Verbo Incarnato, dove la natura umana viene divinizzata ${ }^{30}$. Il vescovo Pietro nel sermone 145, afferma: „Il Verbo si è fatto carne», affinché la carne dell'uomo fosse elevata alla gloria di Dio" ${ }^{31}$. La stessa idea viene ripetuta in un altra omelia con le parole seguenti: ,,avete udito che Dio veniva posto sulla terra e l'uomo in cielo". 32

6. Pienezza del tempo - inizio dei tempi ultimi. Infine, il mistero dell'Incarnazione viene interpretato nella prospettiva escatologica. Il Crisologo rilegge quest'avvenimento come prima parusia. La Vergine accoglie nel suo seno il Giudice celeste che viene per salvare, non per condannare. ${ }^{33}$ L'inizio

${ }^{29}$ Sermo 143, 5, CCL 24B, 873, SPC 3, 118-119.

${ }^{30}$ Cf. Sermo 160, 2, CCL 24B, 990, SPC 3, 220-221: „Unde magus, quia scrutari non ualet, capere non potest, mox adorat. Videt enim non sic lucere in caelo stellas, lunam, solem, qualiter, inluxisse carnem contemplatur in terris. Videt in uno eodemque corpore diuinitatis et humanitatis conuenisse commercium."

${ }^{31}$ Sermo 145, 9, CCL 24B, 897, SPC 3, 136-137.

32 Sermo 142, 1, CCL 24B, 863, SPC 3, 108-109: ,Audistis in terris deum, in caelis hominem sacramento incomprehensibili collocari”. Sermo CXLII, 1. SPC 3, 108.109.

${ }^{33}$ Cf. Sermo 144, 2, CCL 24B, 880, SPC 3, 122-123: „Quid timet, cui iudex causae est adsertor, integritas testis est innocentiae?". 
delle realtà ultime viene messo in rilievo nell'omelia 144 in cui l'Oratore spiega in modo originale l'evento del Natale alla luce di Mt 25,34:

„Egli è nato per noi, è venuto per donarci un regno perché egli stesso lo ha promesso quando ha detto: «Venite, benedetti del Padre mio, ricevete in eredità il regno preparato per voi fin dalla fondazione del mondo»". ${ }^{34}$

E degno di nota che per il nostro vescovo, il termine „giorno del Signore” significa proprio il giorno del Natale ${ }^{35}$. Dunque, l'umanità partecipa già alle realtà ultime sebbene non pienamente.

La venuta al mondo del Messia significa inoltre l'inaugurazione del regno celeste sulla terra. La nascita del Re dei cieli segna l'inizio della sua signoria nel mondo. Il Crisologo, contemplando il Bambino posto in una mangiatoia, con lo stupore esclama: ,giace in fasce, ma regna nei cieli, si umilia in una culla, ma tuona tra le nubi". ${ }^{36}$ Il Re divino, venendo al mondo, estende il suo regno sulla terra. All'umanità è offerta la possibilità di partecipare al regno celeste e di regnare insieme a Cristo. ${ }^{37}$

\section{LA VERGINE MARIA NELLA PIENEZZA DEI TEMPI}

Dopo aver delineato il mistero della nascita di Cristo nella prospettiva storico-salvifica, conviene, ora, porre la domanda: quale posto occupa la Vergine Maria nella pienezza del tempo? Come afferma Pietro Crisologo la Vergine Maria anticipa i tempi nuovi. Ella, durante l'Annunciazione, viene preparata ad accogliere il Verbo divino ottenendo la pienezza della grazia ${ }^{38}$. La grazia ricevuta la santifica e fa, di Maria la primogenita degli uomini, rendendola partecipe della salvezza ancora prima dell'Incarnazione. ${ }^{39}$ In Maria si

${ }^{34}$ Sermo 144, 7, TM 3, 445 (TM = Testi mariani del primo millenio, voll. 1-4, Città Nuova Editrice, Roma 1988-1991).

${ }^{35}$ Cf. Sermo 131, 11, CCL 24B, 808, SPC 3, 50-51: „«Respondit Iesus: Abraham exultauit, ut uideret diem meum: et uidit et gauisus est. Dixerunt Iudaei: Abraham mortuus est». Ille, ut ostenderet uiuere Abraham, dixit illum uidisse diem suum, id est, diem, quo mundo natus est Christus."

${ }^{36}$ Sermo 140 ter, 3, CCL 24B, 856, SPC 3, 100-101: „Iacet in pannis, sed regnat in caelis, humiliatur in cunabulis, sed in nubibus tonat; in praesepe ponitur.”

37 Cf. Sermo 144, 8, CCL 24B, 884, SPC 3, 126-127: „Qui in caelo semper consedit patri, nunc sedem Dauid accepit in terra. Qui regnauit sibi semper, modo nobis in domum Iacob regnum sortitus est aeternum. Gaudeamus, fratres, quia qui sibi regnauit, regnaturus est nobis. Gaudeamus, quia ueniet regnaturus in terram, ut nos cum illo regnare possimus."

${ }^{38}$ Cf. Sermo 140, 3, CCL 24B, 847, SPC 3, 90-91: „Haue, hoc est, accipe gratiam; ne trepides, ne sis sollicita de natura. Plena, quia in aliis gratia, in te tota gratiae pariter ueniet plenitudo."

${ }^{39}$ Cf. Sermo 143, 5, CCL 24B, 873, SPC 3, 118-119: „Quia singulis gratia se est largita per partes, Mariae uero simul se totam dedit gratiae plenitudo. Omnes, inquit euangelista, de plenitudine eius accepimus." 
chiude l'epoca della maledizione iniziata da Eva, e si aprono i tempi nuovi, i tempi della benedizione:

„Perché ora Maria benedetta gode è onorata, è contemplata per quei motivi per i quali Eva puniva le maledette sue viscere. Ed ora è divenuta veramente madre dei viventi secondo la grazia quella che prima era madre dei morenti secondo la natura" 40

In confronto con la prima donna nominata dal Crisologo madre dei morienti, Maria viene chiamata „Madre dei viventi”. Ella, piena di grazia, precede ed preannuncia la salvezza e la pienezza del tempo.

Come afferma il Predicatore ravennate, la Vergine grazie al suo „fiat", collabora alla venuta della pienezza del tempo. Il mistero che si compie nel suo seno, la rende quale aurora dei tempi nuovi. La pienezza dei tempi hanno inizio da Maria e in Maria. Le parole contenute nell'omelia 142 illustrano eminentemente tutto ciò:

„Vergine, ha avuto principio da te il tuo Creatore, da te ha origine la tua Origine, nel tuo germoglio c'è il tuo Genitore, nella tua carne il tuo Dio, e per tuo mezzo ha veduto la luce del mondo Colui che al mondo ha dato la luce". 41

La Serva del Signore viene presenta nella pienezza dei tempi come vergine e madre. Come vergine, sperimenta e gode dei benefici dei tempi nuovi: il Figlio, non solo non rompe l'integrità verginale di sua madre, ma la santifica. La Vergine lo partorisce senza provare i dolori.

Infine occorre sottolineare che per Pietro Crisologo, la Vergine Maria non solo sperimenta in sè i benefici dei tempi nuovi, ma come madre collabora al loro avveramento. In uno dei suoi sermoni il vescovo esprime le parole seguenti: „Giustamente, dunque, tutto è salvo per la Vergine, poiché generò il Salvatore di tutti”. ${ }^{42}$

\section{LA NASCITA DI CRISTO COME PIENEZZA DEI TEMPI NELLA VITA DELLA CHIESA}

La pienezza dei tempi iniziata con l'Incarnazione trova la sua continuazione nella vita della Chiesa. Essa, come vergine e madre concepisce e partorisce nuovi figli:

40 Sermo 140, 4, CCL 24B, 847, SPC 3, 92-93.

${ }^{41}$ Sermo 142, 7, CCL 24B, 866, SPC 3, 112-113.

42 Sermo 144, 5, CCL 24B, 882, SPC 3, 124-125: „Merito Virgini salua sunt omnia, quia omnium genuit Saluatorem." 
„Ormai rinati, come abbiamo detto, a somiglianza del nostro Signore - poiché senza dubbio siamo stati come lui concepiti da una vergine - lo Spirito ci ha infuso la vita, il pudore ci ha portati in grembo". ${ }^{43}$

Come si può notare, la nascita del Salvatore diventa una categoria che permette di rileggere il sacramento del Battesimo come concepimento oppure parto della Vergine. Dunque, la Chiesa non solo annunzia i tempi nuovi, ma anche li rende presenti, effondendo la grazia per mezzo dei sacramenti. Così, l'evento storico-salvifico diventa non solo oggetto della commemorazione, ma della celebrazione liturgica ${ }^{44}$. La liturgia attualizza l'evento storico durante la celebrazione, perciò il Predicatore, rivolgendosi ai fedeli durante la festa dell'Epifania ha potuto esclamare che proprio „oggi il mago trovò vagiente nella culla Colui che cercava fulgido tra le stelle. Oggi il mago ammira luminoso nelle fasce quello che a lungo sopportava oscuro tra le stelle" ${ }^{45}$. Giustificazione di tale celebrazione trova nell'atteggiamento dei Magi:

„Anche noi, fratelli, glorifichiamo con canti e onoriamo con doni la nascita di Cristo, perché il cristiano mente alla sua fede se non fa quello che fecero i Magi" ${ }^{46}$.

L'Oratore, interpretando la visita e l'adorazione dei Magi, spiega alla comunità cristiana il senso della celebrazione natalizia ed invita sia alla contemplazione dei misteri della nostra salvezza, che alla loro celebrazione liturgica $^{47}$.

La teologia di Pietro Crisologo, presentata nella prospettiva storico-salvifica, presenta l'evento dell'Incarnazione come il culmine della storia dell'umanità. L'irruzione di Dio nel tempo conferisce alla storia, valore salvifico. L'assunzione della natura umana da parte del Verbo eterno del Padre, se da una parte ha significato la sua umiliazione, dall'altra è rivelazione di una dimensione della temporaneità. La venuta della pienezza dei tempi, viene presentata da

43 Sermo 117, 5, CCL 24A, 711, SPC 2, 376-377.

44 Cf. Sermo 157, 1, CCL 24B, 976, SPC 3, 204: „Dominicae festiuitates causas suas suis uocabulis eloquuntur, nam sicut nascendo Christus diem dedit natalem, et resurgendo resurrectionis diem dedit, sic lumine signorum diem suae inluminationis effudit."

45 Sermo 160, 2, CCL 24B, 989, SPC 3, 220-221.

46 Sermo 91, 8, CCL 24A, 568, SPC 2, 216-217.

47 Cf. Sermo 103, 6, CCL 24A, 643-644, SPC 2, 296-197: „Verum quia nascentis Christi uenit tempus, et miraculum caeleste iam radiat paritura uirginitas, atque ortum diuini regis non stella iam nuntiat, sed ipse solis ascensus, adoraturi occurramus omnes, et muneribus sacris deum regemque uirgineo processisse fateamur ex templo. Offeramus munera, quia nascenti regi semper publica paratur oblatio. Offeramus munera, quia indeuotus satis est uacuus adorator." 
Pietro Crisologo compimento delle promesse vetero-testamentarie e rivelazione del Dio invisibile. Contemplando la straordinarietà dell'evento, l'autore sottolinea la dimensione soteriologica dell' Incarnazione. Nei suoi sermoni viene evidenziato inoltre l'aspetto escatologico del Natale, che considerato in tale prospettiva annunzia l'inizio dei tempi ultimi. Nel discorso nettamente cristocentrico, viene situata la figura di Maria la quale, nella novità dei tempi, svolge un ruolo particolare: Ella preannunzia la nuova economia salvifica, accoglie e partecipa ai benefici della nuova realtà, infine, partorendo il Salvatore, coopera alle venute dei tempi nuovi i quali trovano il loro prolungamento, nella vita liturgica della Chiesa; la celebrazione dei sacramenti viene considerata come continuazione dell'evento della nascita di Cristo.

Concludendo, è opportuno notare che san Pietro Crisologo non ha dedicato al concetto del tempo un'attenzione particolare, ma nonostante ciò, i dati di detto concetto, sparsi nei suoi 183 sermoni, che abbiamo colto e presentato, ce ne mostrano un'immagine preziosa ed interessante, degna della nostra attenzione.

\section{DZIEWICA MARYJA I PEŁNIA CZASÓW W TAJEMNICY WCIELENIA WEDŁUG ŚW. PIOTRA CHRYZOLOGA}

\section{(Streszczenie)}

Tajemnica Wcielenia odgrywa w teologii św. Piotra, zwanego Zlotosłowym, pierwszorzędną rolę. Wydarzenie to, ukazane w perspektywie historio-zbawczej, jawi się jako moment kulminacyjny dziejów ludzkości, które dzieli historię na dwie części: przed i po Chrystusie i nadaje jej prawdziwy, autentyczny sens. Odczytane w takiej perspektywie dzieje ludzkości objawiają zbawczy zamysł Boga i ukazują jego realizację. Epoka poprzedzająca przyjęcie Jezusa jawi się jako czas przygotowania ludzkości na przyjęcie Zbawiciela. Owo przygotowanie polega na stopniowym objawianiu się miłości Bożej do człowieka, która wyzwala go ze strachu. Bóg pragnie, aby człowiek nauczył się Go kochać, a nie by odnosił się do Niego z bojaźnią. W ekonomi Bożej na przyjęcie Mesjasza, przygotowywany jest nie tylko naród żydowski, lecz również poganie. Bóg wzbudza w nich pragnienie zobaczenia Go, co zostaje wyrażone w kulcie bożków. Jahwe, według Piotra Chryzologa, w swoim zbawczym planie wytyczył ludzkości kolejne etapy: okres przed nadaniem Prawa, okres Prawa i czas łaski, który rozpoczyna się wraz z przyjęciem Zbawiciela.

Metropolita Rawenny, w komentarzu tajemnicy Wcielenia, uwypukla niektóre cechy właściwe Synowi Bożemu: wieczność, niezmienność, ponadczasowość. Poprzez wprowadzenie określeń „Auctor temporum” i „Conditor dierum” Piotr Chryzolog usiłuje podkreślić, iż Syn, stwarzając świat, nie tylko zapoczątkował bieg 
historii, lecz będąc wobec niej transcendentny, prowadzi ją do swojej pełni. Poprzez Wcielenie w osobie Chrystusa jednoczą się rzeczywistości dotychczas sobie przeciwne: bóstwo i ludzkość, ziemia i niebo, wieczność i czas. Chwila, w której Słowo stało się ciałem jest interpretowana jako uniżenie, jako poddanie się Tego, który przekracza czasowość, regułom czasu. W taki oto sposób czasowość, przemijalność staje się wymiarem Boga. Lecz z drugiej zaś strony, Bóg poprzez zjednoczenie z sobą ludzkiej natury, nadaje kategorii czasu prawdziwą wartość zbawczą. Przyjście na świat Mesjasza zapoczątkowuje pełnię czasów. Owa pełnia oznacza dla Piotra Chryzologa czas wypełnienia się starotestamentalnych obietnic. Narodziny Mesjasza są również objawieniem się Niewidzialnego. Czas oczekiwania zostaje wypełniony a pragnienie zobaczenia Boga zaspokojone. Bóg dotychczas niewidzialny w Chrystusie staje się widzialny.

Moment Wcielenia zostaje odczytany również jako początek nowego stworzenia. Syn Boży, jednocząc się z naturą ludzką, oczyszcza ją z grzechu i dokonuje jej przebóstwienia, udzielając pełni swego życia. Dzięki wydarzeniu Wcielenia, człowieczeństwo uczestniczy w boskiej chwale. Warto zaznaczyć, iż pełnia czasów w interpretacji Piotra Chryzologa jest ściśle powiązana $\mathrm{z}$ wątkiem eschatologicznym: nadejście niebiańskiego Sędziego wiąże się ze zbawianiem a nie z potępianiem. Dzień jego przyjścia na świat jest nazwany przez Biskupa Piotra „dniem Pańskim”.

Perspektywa historio-zbawcza tajemnicy Wcielenia rozciąga się także na postać Błogosławionej Dziewicy Maryi, która rozważana w takim świetle antycypuje nowe czasy. Podczas Zwiastowania, otrzymując pełnię łaski, zostaje przygotowana na przyjęcie Syna Bożego. Udzielona łaska nie tylko uświęca Maryję, lecz powoduje, że epoka „przekleństwa” Ewy zostaje definitywnie zakończona, i zapoczątkowuje nową epokę, czas błogosławieństwa. Pokorna Służebnica Pańska jest pierwszą błogosławioną pomiędzy niewiastami. Jej rola w ekonomii zbawczej wyraża się między innymi w czynnej współpracy w urzeczywistanianiu się pełni czasów. Wydarzenie Wcielenia dokonuje się dzięki Jej „fiat”. Natomiast nosząc w swym łonie Syna Bożego, Dziewica Maryja staje się jutrzenką nowych czasów. W tym świetle łatwo o stwierdzenie że pełnia czasów rozpoczyna się od Maryi i w Maryi.

Nowa epoka, zapoczątkowana poprzez przyjście na świat Zbawiciela, znajduje swoją kontynuację w życiu Kościoła, który, nie tylko oznajmia nadejście nowych czasów, lecz również je aktualizuje, udzielając Bożej łaski poprzez sprawowane sakramenty. Chryzolog zwraca uwagę na zachodzącą analogię: Kościół, dziewica i matka, na wzór Maryi Dziewicy i Matki, poczyna i rodzi Chrystusa. Konkludując należy stwierdzić, że chociaż św. Piotr Chryzolog w swoich 183 kazaniach nie poświęcił zagadnieniu pełni czasów jakiegoś obszernego fragmentu, to jednak, informacje, które zostały przez nas zebrane i przedstawione, ukazują obraz niezwykle interesujący, ze wszech miar godny naszej uwagi. 